\title{
ANÁLISIS GENÉTICO POBLACIONAL DE GRUPOS CAZADORES RECOLECTORES DEL HOLOCENO TARDÍO DEL LAGO SALITROSO (SANTA CRUZ, ARGENTINA)
}

\author{
POPULATION GENETIC ANALYSIS OF HUNTER-GATHERER GROUPS \\ FROM THE LATE HOLOCENE OF THE SALITROSO LAKE (SANTA CRUZ, \\ ARGENTINA)
}

\author{
Valeria Arencibia ${ }^{1,2 * \S}$, Cristian M. Crespo ${ }^{1,2 \S}$, Solana García Guraieb ${ }^{1,3}$, María G. Russo ${ }^{1,2}$, \\ Cristina B. Dejean ${ }^{2,4}$ y Rafael Goñi ${ }^{3}$
}

\author{
${ }^{1}$ Consejo Nacional de Investigaciones Científicas y Técnicas (CONICET) \\ ${ }^{2}$ Centro de Estudios Biomédicos, Biotecnológicos, Ambientales y Diagnóstico (CEBBAD). Equipo de Antropología Biológica. Uni- \\ versidad Maimónides. Buenos Aires. Argentina \\ ${ }^{3}$ Instituto Nacional de Antropología y Pensamiento Latinoamericano (INAPL). Buenos Aires. Argentina \\ ${ }^{4}$ Instituto de Ciencias Antropológicas. Sección de Antropología Biológica. Facultad de Filosofía y Letras. Universidad de Buenos \\ Aires. Buenos Aires. Argentina \\ ${ }^{\S}$ Estos autores contribuyeron de igual manera al presente trabajo
}

\section{PALABRAS CLAVE Lago Salitroso; ADN antiguo; linajes maternos}

RESUMEN Durante el Holoceno tardío la dinámica poblacional humana en Patagonia estuvo condicionada por factores ambientales, debido a que la tendencia hacia condiciones de mayor aridez afectó sustancialmente las cuencas hídricas y sus ambientes asociados. En particular, para la cuenca del Lago Salitroso (noroeste de la actual provincia de Santa Cruz, Argentina), se propuso una reducción de la movilidad residencial, con un consecuente nucleamiento poblacional en torno a esta fuente de agua permanente. En este trabajo se abordaron problemáticas arqueológicas sobre la población del Lago Salitroso a través del estudio del ADN mitocondrial antiguo. Con el fin de evaluar la composición genética de la población del lago, y detectar una posible expansión poblacional, se procesaron restos óseos y dentales de 28 individuos, con cronología entre 2600 y 300 años
AP. Se logró extraer ADN y analizar la Región Hipervariable I en 16 muestras. Las secuencias obtenidas permitieron identificar cuatro linajes maternos: D1g (43,7\%), B2 (31,3\%), C1 (18,8\%) y D4h3a $(6,2 \%)$. Parte de los individuos presentaron haplotipos derivados, muchos de ellos hallados únicamente en la cuenca. Resulta interesante la presencia del linaje B2, ya que se encuentra escasamente descripto para poblaciones prehispánicas en Patagonia. Además, se observó una alta variabilidad genética en la muestra analizada, y una diferenciación respecto de otras poblaciones antiguas patagónicas. Por otro lado, si bien los análisis arqueológicos más recientes sugieren un crecimiento poblacional durante los últimos 500 años de ocupación de la cuenca, no se encontraron evidencias genéticas de dicho proceso. Rev Arg Antrop Biol 21(2), 2019. doi:10.24215/18536387e004

\section{KEY WORDS Salitroso Lake; ancient DNA; maternal lineages}

ABSTRACT During the Late Holocene, human population dynamics in Patagonia was conditioned by environmental factors, since a climate shift towards more arid conditions affected watersheds and their associated environments. In particular, for the Salitroso Lake basin (northwest of Santa Cruz province, Argentina) has been proposed a reduction in residential mobility, with a consequent population nucleation around this permanent water source. In this study, some archaeological concerns about the Salitroso Lake population were addressed through the study of ancient mitochondrial DNA. In order to evaluate the genetic composition of the lake's inhabitants and detect a possible population expansion, skeletal remains of 28 individuals (dated between 2,600 and 300 years BP) were processed. We were able to extract DNA and analyze the Hipervariable Region I of the mitochondrial genome in 16 samples. Four maternal lineages were found: D1g (43,7\%), B2 (31,3\%), C1 (18,8\%) and D4h3a $(6,2 \%)$. Some individuals presented derived haplotypes, many of them only found in the basin. The presence of the B2 lineage is interesting, since it has been scarcely described in pre-Hispanic groups in Patagonia. In addition, high levels of genetic variability were observed in the analyzed sample, which was also different from other ancient Patagonian populations. Although the most recent archaeological analyses suggest a population growth during the last 500 years of occupation of the basin, no genetic evidence of this process was found. Rev Arg Antrop Biol 21(2), 2019. doi: 10.24215/18536387e004

Financiamiento: ANPCyT (PICT 2014-3012; BID PICT 2014-1558). UBACyT 20020150200233BA (2016). Fundación Científica Felipe Fiorellino (Subsidio Intramuros 2017). Fundación de Historia Natural Félix de Azara (Subsidio Intramuros 2017).

*Correspondencia a: Valeria Arencibia. CEBBAD. Universidad Maimónides. Hidalgo 775, 6to piso Departamento 602. C1405BCK Buenos Aires. Argentina. E-mail: aren.vale@gmail.com

Recibido 06 Septiembre 2018; aceptado 18 Febrero 2019

doi: $10.24215 / 18536387 \mathrm{e} 004$ 
Los análisis genéticos de genomas mitocondriales completos realizados hasta el momento en poblaciones nativas americanas actuales han establecido que son al menos 16 los haplogrupos fundadores que han ingresado a América con los primeros pobladores (Achilli et al., 2013). Sólo ocho de los 16 (A2, B2, C1b, C1c, C1d, C4c, D1 y D4h3a) son linajes pan-americanos, ya que se encuentran distribuidos en todo el continente (Tamm et al., 2007). En el Cono Sur de Sudamérica puede hablarse, en líneas generales, de una disminución de la variabilidad genética mitocondrial siguiendo un gradiente norte-sur, siendo Patagonia la región con menos linajes representados, posiblemente como consecuencia de la deriva genética (Moraga et al., 2000; Moraga, de Saint Pierre, Torres y Ríos, 2010). Los estudios hechos hasta el momento en poblaciones nativas actuales de dicha región demuestran la prevalencia de los linajes C1, D1 y D4h3a en el sur de la Patagonia, mientras que A2 y B2 se encuentran restringidos al norte patagónico (Moraga et al., 2000; de Saint Pierre et al., 2012 a y b).

Gran parte de los trabajos realizados sobre ADN antiguo ( $A D N a)$ en la Patagonia encuentran el mismo patrón de reducción de la variabilidad genética hacia el sur (de la Fuente et al., 2015; García-Bour et al., 2004; Lalueza, Pérez-Pérez, Prats, Cornudella y Turbón, 1997; Moraga et al., 2010;). Sin embargo, algunos estudios hallaron en grupos prehispánicos variantes genéticas no observadas en poblaciones actuales. Es el caso de Reyes, Méndez Melgar, Mena y Moraga (2012), cuyo análisis de restos humanos del sitio Baño Nuevo 1 (datado en aproximadamente 10.000 años cal AP) estableció la presencia del haplogrupo B en la Patagonia chilena. Este linaje fue también hallado recientemente en individuos del Río Bote (Santa Cruz, Argentina) con una temporalidad hacia el Holoceno tardío (Franco, Galimany, Moraga y Borrero, 2017). Esto sugiere que la discontinuidad observada para el linaje B entre poblaciones antiguas y actuales del sur de la Patagonia puede deberse a un proceso de deriva genética reciente, o bien a un sesgo muestral. En sus recientes trabajos, Crespo y colaboradores (Crespo, Dubois, Russo, Lanata y Dejean, 2017a; Crespo, Russo, Hajduk, Lanata y Dejean, 2017b) identificaron individuos portadores del linaje A2 en Norpatagonia andina y costera, aumentando la cantidad de linajes reconocidos en la región en tiempos prehispánicos.

\section{Dinámica poblacional en la región del Lago Salitroso}

La cuenca del Lago Salitroso (Fig. 1), ubicada al noroeste de la actual provincia de Santa Cruz, posee un registro arqueológico situado temporalmente en los últimos 2700 años AP (Goñi, 2010). Hacia esa cronología se registra en la región una disminución de la humedad, cuyo pico más agudo fue en el evento climático global conocido como Anomalía Climática Medieval (ACM; Stine y Stine, 1990), detectándose entre $c a .900$ y 750 años AP "sequías épicas" (Stine, 1994). Esto provocó la merma de recursos hídricos regionales, tales como las cuencas de los lagos Posadas/Pueyrredón y Salitroso (Horta y Aschero, 2010) y el lago Cardiel (Ariztegui et al., 2014).

Se ha propuesto que los cambios en las condiciones ambientales de la región durante el Holoceno tardío habrían generado una reducción de la movilidad residencial de los grupos humanos, así como un nucleamiento ${ }^{1}$ de sus asentamientos en lugares específicos, con disponibilidad de agua permanente y buenas condiciones para la habitación humana, tales como la cuenca del Lago Salitroso (Cassiodoro, 2011;García Guraieb, 2010; García Guraieb, Goñi y Tessone, 2015; Goñi, 2010; Goñi, Barrientos y Cassiodoro, 2000-2002; Tessone, 2010; Tessone et al., 2009; entre otros).

Hasta el momento se han identificado en la misma 97 individuos en 37 estructuras formales de entierro, que pueden agruparse por sus características en tres grupos: nichos, entierros bajo bloque y chenques (García Guraieb et al., 2015). Asimismo, según sus fechados radiocarbónicos se han determinado tres grupos cronológicos: uno temprano constituido por cinco nichos y cinco entierros bajo bloque ( $c a .2600 \mathrm{y}$ 2200 años AP), otro conformado por dos estructuras de "chenques inciales" ( $c a .1600$ y 1200 AP), y un grupo tardío mayoritario formado por 25 "chenques tardíos" ( $c$ a. 800 y $350 \mathrm{AP}$ ) (García Guraieb, Goñi y Guichón Fernández, 2018; García Guraieb et al., 2015).

Si bien en el sector del Lago Salitroso los 


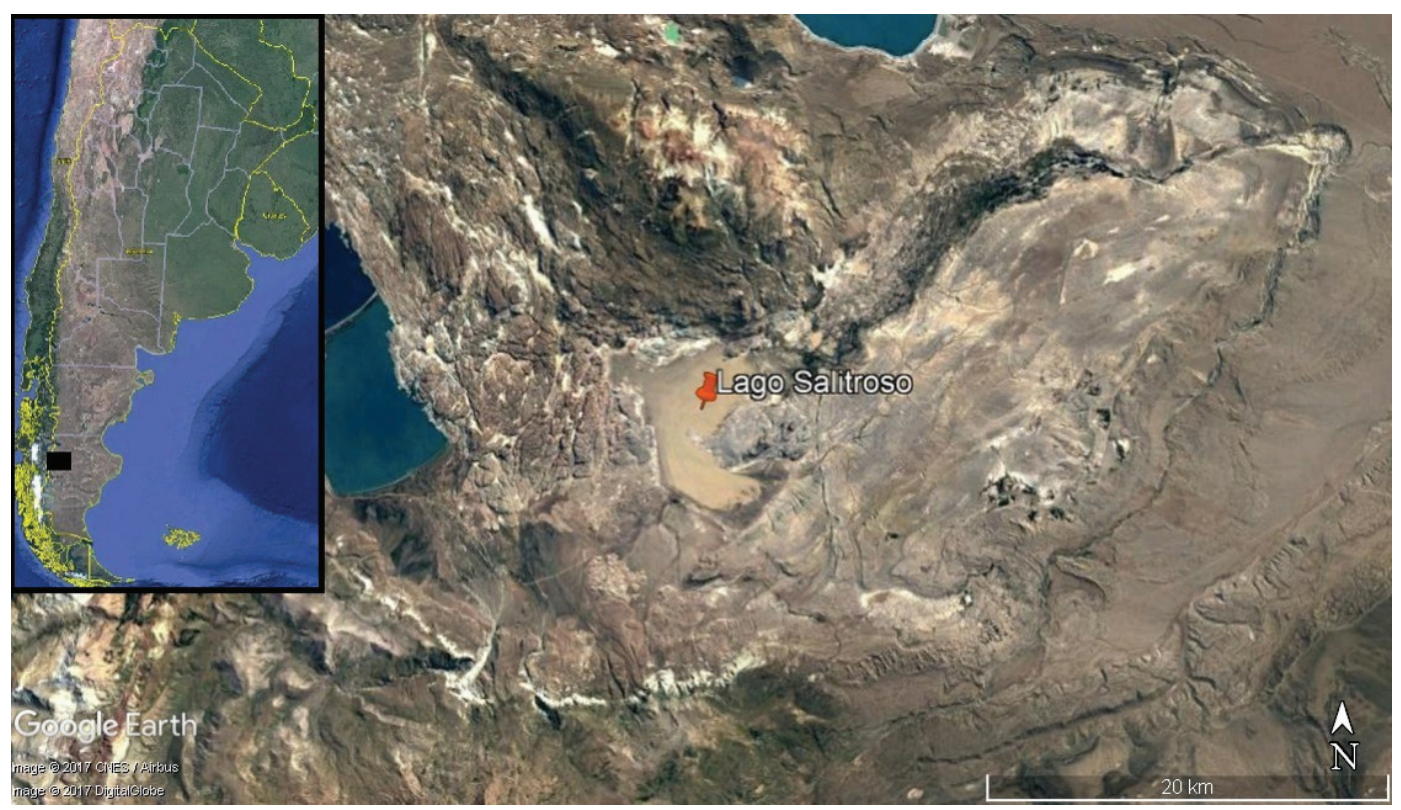

Fig. 1. Ubicación geográfica del área de estudio. Lago Salitroso, Santa Cruz, Argentina.

entierros y los sitios a cielo abierto mencionados no muestran una cronología continua, existe un continuum ocupacional de más de 3500 años con cuencas cercanas, con las que comparte características geomorfológicas, ambientales y arqueológicas, como las de los lagos Posadas y Pueyrredón (De Nigris, Figuerero Torres, Guráieb y Mengoni Goñalons, 2004; García Guraieb et al., 2015; Goñi et al., 2000-2002).

Los análisis bioarqueológicos realizados sobre los individuos de las primeras ocupaciones de la cuenca hasta los últimos enterratorios, han permitido postular que dicha región habría sido ocupada por grupos biológicamente vinculados, y con cierto grado de continuidad poblacional (Béguelin, 2009; Bernal, 2008; García Guraieb, 2010; Perez, Beguelin y Del Papa, 2004). La evidencia aportada por los estudios de isótopos estables de ${ }^{13} \mathrm{C}$ y ${ }^{15} \mathrm{~N}$ sustenta dicha continuidad, ya que la señal paleodietaria identificada durante todo el período considerado se presenta homogénea y característica de una estepa occidental (Tessone, 2010; Tessone et al., 2009).

La alta concentración de entierros humanos con cronologías correspondientes al Holoceno tardío es un rasgo distintivo del registro del área frente a la dispersión y escasez del mismo en el resto de la Patagonia. Además, se ha registrado principalmente en los últimos 900 años AP una alta frecuencia de sectores interpretables como campamentos, aledaños a los lugares de entierros (Cassiodoro et al., 2004), entre los que se encuentran tecnologías asociada a tareas domésticas habituales (Cassiodoro 2011). En relación a esto, las últimas formulaciones del modelo de ocupación plantean que, con posterioridad al pico de mayor aridez de la ACM, el área del Lago Salitroso habría sido empleada en forma más residencial y estable por grupos que estarían experimentado cierta recuperación poblacional después de los siglos de aridez extrema precedentes (García Guraieb, 2010; García Guraieb et al., 2015; Goñi, 2010). El reciente análisis de diferentes líneas de evidencia arqueológica y bioarqueológica de García Guraieb y colaboradores (2015) remarca la alta representación de subadultos (individuos menores a 10 años) en el grupo de chenques tardíos, lo cual podría ser explicado por un escenario de fecundidad creciente, entre otras hipótesis. Asimismo, este último conjunto de chenques conforma un área formal de entierro, algo poco frecuente en Patagonia meridional (Goñi et al., 2000-2002) y constituye uno de los indicadores más fuertes de que la tendencia hacia condiciones de menor movilidad residencial iniciada durante los últimos 2700 años, se habría intensificado sustancialmente durante el último milenio. 
Teniendo en cuenta lo expuesto, resulta de interés conocer si la evidencia que arroja el registro arqueológico y los estudios bioantropológicos respecto a las dinámicas demográficas en el Lago Salitroso encuentran un correlato desde el punto de vista genético. Conforme a ello, el objetivo de este trabajo consiste en ampliar el conocimiento de la población que ocupó el Lago Salitroso durante el Holoceno tardío. Se propone específicamente analizar la variabilidad genética mitocondrial en el contexto patagónico, y detectar a través de este estudio, si existió un proceso de expansión en dicha población.

\section{MATERIAL Y MÉTODOS}

\section{Muestras analizadas}

Se tomaron restos óseos y dentales de 28 individuos procedentes de diferentes entierros de la cuenca del Lago Salitroso, cuyo fechado se extiende entre 2600 y 300 años AP (García Guraieb et al., 2015) (Tabla 1).

\section{Procesamiento de las muestras}

Para las piezas dentales, se obtuvo el polvo de dentina por desbaste interno de la corona siguiendo la técnica reportada en trabajos previos (Dejean, Crespo, Carnese y Lanata, 2014; Kuch et al., 2007). Los fragmentos de huesos y las piezas dentales cuyo estado de conservación no permitió la extracción de dentina, fueron molidos siguiendo los protocolos descriptos en Carnese et al. (2010). Para cada muestra se realizaron dos extracciones de ADN independientes, las cuales se llevaron a cabo siguiendo la metodología descripta en Arencibia (2018). Se secuenció la Región Hipervariable I (HVR I) del genoma mitocondrial, utilizando los cebadores y las condiciones de reacción descriptas por Russo, Gheggi, Avena, Dejean y Cremonte (2017). La secuenciación se llevó a cabo en un secuenciador automático 3130XL Genetic Analyzer con BigDyeTM Terminator Sequencing Kit (Applied Biosystems), en la Unidad de Genómica del Instituto de Biotecnología del INTA (Hurlingham, Buenos Aires). Para cada extracto se obtuvieron secuencias de al menos dos amplificaciones diferentes por fragmento.
Las mutaciones fueron identificadas mediante el alineamiento con la rCRS (Andrews, Kubacka, Chinnery, Lightowlers y Turnbull, 1999). Para cada individuo se determinó una secuencia final consenso para la HVR I a partir de todos los fragmentos secuenciados, considerándose únicamente aquellas mutaciones que estuvieran presentes en la mayoría de las secuenciaciones. Ésta fue comparada con las disponibles en bibliografía (PhyloTree 17; van Oven y Kayser, 2009) mediante el programa Haplogrep 2 (Weissensteiner et al., 2016).

\section{Prevención de la contaminación y autenticidad}

En este trabajo se aplicaron los procedimientos establecidos en la literatura para el análisis de $A D N a$ (e.g. Kemp y Smith, 2010), destinados principalmente a evitar la contaminación y obtener resultados confiables. En primer lugar, todos los procesamientos previos a la amplificación por PCR fueron llevados a cabo en una campana de flujo laminar que evita el intercambio de aire con el exterior y se realizaron en un laboratorio aislado del sector destinado a procedimientos post-PCR. Todas las superficies y materiales de trabajo fueron limpiados con una solución de agua lavandina comercial 10\% y/o etanol $70 \%$, e irradiados con luz UV durante al menos $45^{\prime}$ antes y después de su utilización. Todos los procedimientos se llevaron a cabo usando indumentaria previamente irradiada con luz UV: guardapolvo, cofia, barbijo y doble par de guantes.

Se incluyeron tanto blancos de extracción como de PCR a fin de controlar que no hubiera contaminación con ADN exógeno durante todos los procedimientos.

Por último, con el objetivo de detectar posibles fuentes de contaminación humana, se analizaron los haplotipos mitocondriales de los investigadores que tuvieron contacto con las muestras analizadas y con las áreas de trabajo.

\section{Análisis estadístico}

\section{Base de datos}

Con el fin de comparar los resultados obtenidos para los individuos del Lago Salitroso, se incorporaron al estudio secuencias de otros 
grupos antiguos de la Patagonia recopilados de la literatura. Se estudiaron un total de 86 individuos, agrupados siguiendo un criterio geográfico en: Norpatagonia, Costa de Santa Cruz, Lago Salitroso, Kawéskar y Yámana (Material suplementario, Tabla S1).

\section{Variabilidad genética poblacional}

A fin de comparar la variabilidad genética de la población analizada en el presente trabajo con la de otros grupos antiguos de Patagonia, se estimaron diversos estadísticos de variabilidad: el número de haplotipos (h), la diversidad haplotípica $(\mathrm{Hd})$, la diversidad nucleotídica $(\pi)$ y el estimador de Watterson $\left(\theta_{\mathrm{s}}\right)$. Todos los estadísticos fueron calculados con el programa DnaSP v.5.10.01 (Librado y Rozas, 2009).

\section{Diferenciación genética}

Para evaluar la diferenciación genética entre los grupos poblacionales antiguos analizados en la Patagonia (Material suplementario, Tabla S1), se realizó un Análisis Molecular de la Varianza (AMOVA) con el programa Arlequin v.3.5.2.2 (Excoffier y Lischer, 2010). Se calcularon los estadísticos $\mathrm{F}_{\mathrm{ST}}\left(\Phi_{\mathrm{ST}}\right)$ linealizados (Slatkin, 1995) entre pares de poblaciones, y se realizaron 1000 permutaciones para obtener la significación ( $\operatorname{con} \alpha=0,05)$. El modelo de evolución molecular utilizado fue $\mathrm{TN} 93+\mathrm{G}(\mathrm{G}=0,231$; Tamura y Nei, 1993), elegido con el programa MEGA 6 (Tamura, Stecher, Peterson, Filipski y Kumar, 2013).

\section{Análisis de redes de haplotipos}

Se estudió la distribución de los linajes obtenidos en los individuos del Lago Salitroso en otras poblaciones de la región, antiguas y nativas actuales (Tabla S1). Se construyeron redes de haplotipos para los haplogrupos mitocondriales B2, C1, D1 y D4h3a, con el método Median Joining (Bandelt, Forster y Röhl, 1999) utilizando el programa Network v.5.0.0.1 (http://www.fluxus-engineering.com). Se asignó a cada sitio polimórfico un peso acorde a las tasas mutacionales descriptas por Soares y colaboradores (2009). Para la red del haplogrupo $\mathrm{B} 2$ no se consideraron las mutaciones en las posiciones 16182 y 16183 por su alta tasa de mutación.

\section{Pruebas de expansión poblacional}

Se calcularon los estadísticos D (Tajima, 1989) y Fs (Fu, 1997), para la población del Lago Salitroso, y su significación se obtuvo mediante la realización de 1000 simulaciones de coalescencia utilizando el programa DnaSP v.5.10.01 (Librado y Rozas, 2009).

\section{RESULTADOS}

Se obtuvieron secuencias reproducibles de la HVR I para 16 de los 28 individuos analizados en este trabajo (57,1\% de éxito en la recuperación de $A D N a$ ). Sin embargo, se observó que la tasa de recuperación dependió del tipo de muestra analizada, ya que para piezas dentales fue de un $93 \%(n=15)$, mientras que para los restos óseos de un $15 \%(\mathrm{n}=13)$.

No se observó contaminación con ADN de los investigadores del Equipo de Antropología Biológica (CEBBAD, Universidad Maimónides) ni de los arqueólogos que cedieron las muestras para su análisis (Material suplementario, Tabla S2).

\section{Variabilidad genética de la población del Lago Salitroso}

En la Tabla 1 se presentan las secuencias para cada individuo y su linaje mitocondrial, según HVR I. Siete individuos del Lago Salitroso analizados pudieron asignarse al haplogrupo D1g, cinco al B2, tres al C1 y uno al D4h3a.

En la Tabla 2 se resumen los resultados del análisis de variabilidad genética. Todos los estadísticos indican que la población del Lago Salitroso posee una alta variabilidad, similar a la hallada en Norpatagonia, siendo estas dos las más variables de las poblaciones antiguas analizadas. Asimismo puede destacarse que la población del lago tiene la mayor cantidad de haplotipos diferentes (12 dentro de los 16 individuos con resultados).

\section{Diferenciación genética entre el Lago Salitroso y otros grupos prehispánicos}

El AMOVA realizado mostró que existe diferenciación genética entre los grupos analizados $\left(\mathrm{F}_{\mathrm{ST}}=0,21311 ; \mathrm{p}<0,00001\right.$; Tabla 3$)$. Las compa- 


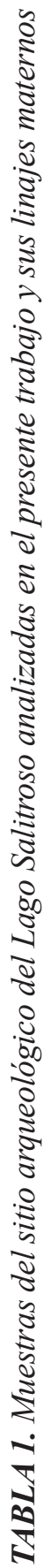

\begin{tabular}{|c|c|c|c|c|c|c|c|c|c|c|c|c|c|c|}
\hline 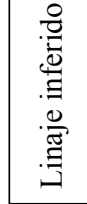 & 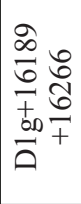 & $\vec{D}$ & $\stackrel{\dot{\lrcorner}}{\dot{I}}$ & $\stackrel{\check{I}}{\dot{I}}$ & $\begin{array}{l}8 \\
0 \\
\mathbb{1} \\
+ \\
\pm \\
\pm \\
\end{array}$ & 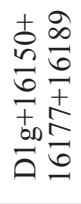 & $\widetilde{\oplus}$ & $\tilde{n}$ & 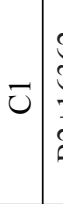 & 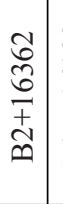 & 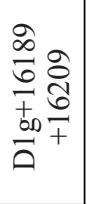 & $\begin{array}{l}\frac{\nabla}{\sigma} \\
\pm \\
\pm\end{array}$ & 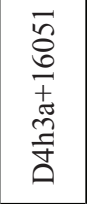 & $\widetilde{c}$ \\
\hline 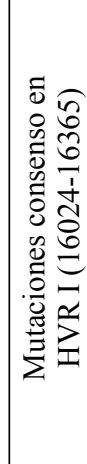 & 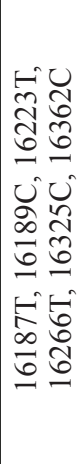 & 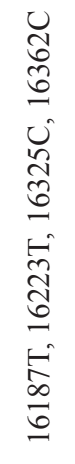 & $\stackrel{\dot{\lrcorner}}{\unlhd}$ & 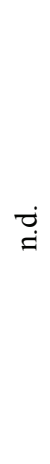 & 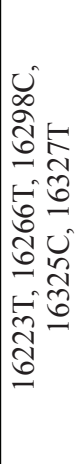 & 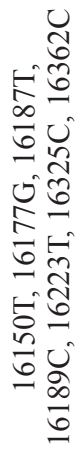 & 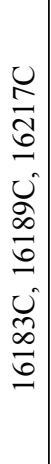 & 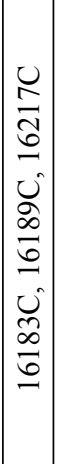 & 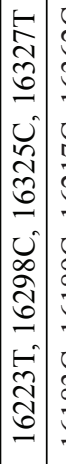 & 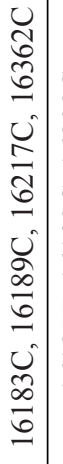 & 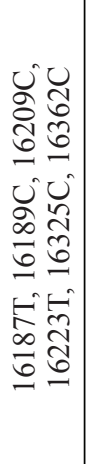 & 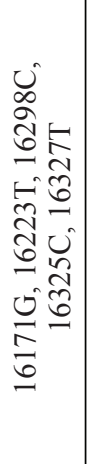 & 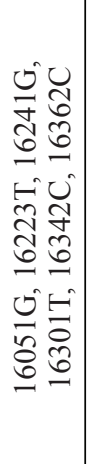 & 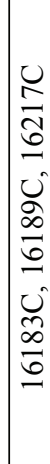 \\
\hline 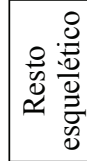 & 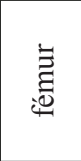 & $\stackrel{\pi}{0}$ & 司 & 悫 & $\begin{array}{l}\text { 离 } \\
\stackrel{\Xi}{\Xi}\end{array}$ & 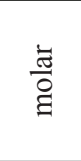 & $\begin{array}{l}\frac{\mathfrak{\Xi}}{0} \\
\stackrel{\Xi}{\Xi} \\
\end{array}$ & $\left|\begin{array}{l}\bar{z} \\
0 \\
\vdots \\
\Xi\end{array}\right|$ & $\mid \begin{array}{l}\tilde{z} \\
0 \\
0 \\
\Xi\end{array}$ & $\begin{array}{l}\frac{\tilde{t}}{0} \\
\stackrel{\Xi}{\Xi}\end{array}$ & $\begin{array}{l}\frac{\bar{t}}{0} \\
\stackrel{\Xi}{\Xi}\end{array}$ & $\begin{array}{l}\frac{\tilde{\sigma}}{\circ} \\
\text { ఏ }\end{array}$ & $\begin{array}{l}\frac{\tilde{\sigma}}{0} \\
\stackrel{\Xi}{\Xi}\end{array}$ & $\begin{array}{l}\frac{\Xi}{\circ} \\
\stackrel{\Xi}{\Xi}\end{array}$ \\
\hline 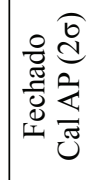 & 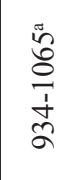 & 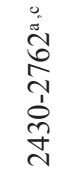 & 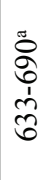 & 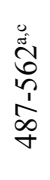 & 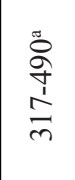 & $\begin{array}{l}\tilde{0} \\
\hat{0} \\
1 \\
0 \\
n \\
n\end{array}$ & 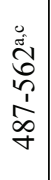 & 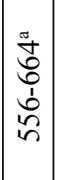 & 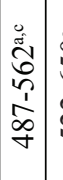 & 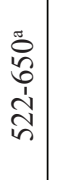 & 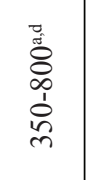 & 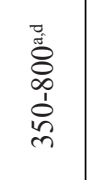 & $\begin{array}{l}n \\
n \\
0 \\
1 \\
1 \\
n \\
n\end{array}$ & 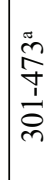 \\
\hline 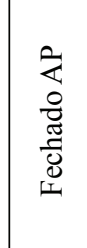 & $\begin{array}{l}\text { N } \\
\text { H } \\
+1 \\
\text { 五 } \\
=\end{array}$ & 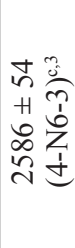 & 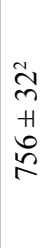 & 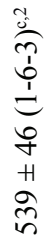 & $\begin{array}{l}+ \\
+ \\
+ \\
+1 \\
\& \\
\infty \\
\text { ñ }\end{array}$ & $\begin{array}{l}\stackrel{2}{7} \\
+1 \\
\stackrel{0}{0}\end{array}$ & 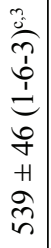 & 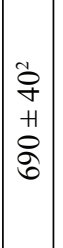 & 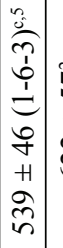 & 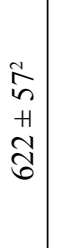 & $\stackrel{\ddot{g}}{\dot{d}}$ & $\stackrel{\check{g}}{\mathrm{~g}}$ & $\hat{\sigma}$ & $\begin{array}{l}\text { ô } \\
+ \\
H \\
\text { N } \\
n\end{array}$ \\
\hline 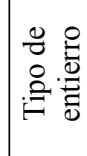 & ]ี & 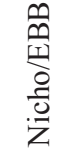 & 光 & 䒕 & 它 & 皇 & $\vec{E}$ & $\begin{array}{l}\vec{E} \\
\mathcal{E}\end{array}$ & $\vec{\Xi}$ & Eี & 苞 & 它 & 皇 & Eี \\
\hline $\begin{array}{l}\overline{7} \\
\bar{\pi} \\
\text { III }\end{array}$ & $\frac{\stackrel{ }{\Xi}}{\frac{7}{\sigma}}$ & 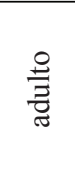 & 导 & ! & $\frac{\stackrel{9}{ }}{\text { 吾 }}$ & 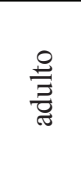 & $\stackrel{?}{g}$ & 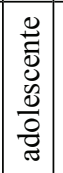 & 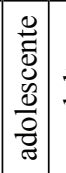 & 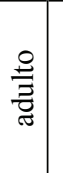 & 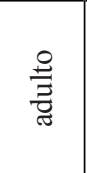 & $\frac{\stackrel{\rho}{ }}{\frac{7}{3}}$ & 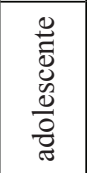 & $\frac{\stackrel{0}{\Xi}}{\text { 워 }}$ \\
\hline 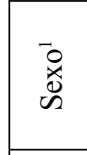 & $\begin{array}{l}\stackrel{\Xi}{\Xi} \\
\Xi \\
. \\
\Xi \\
\Xi \\
\Xi\end{array}$ & $\begin{array}{l}\stackrel{\Xi}{\Xi} \\
\Xi \\
\Xi \\
\Xi \\
\Xi \\
\Xi\end{array}$ & 럼 & ت્ & 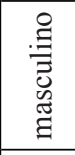 & 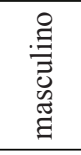 & ت્ટ் & 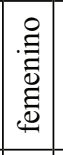 & 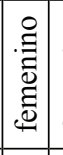 & 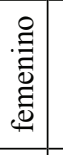 & 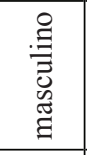 & 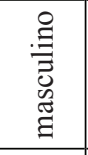 & 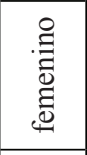 & 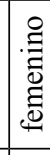 \\
\hline 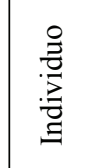 & 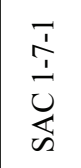 & 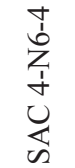 & 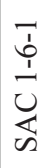 & 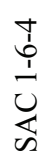 & 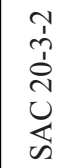 & 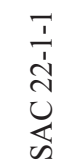 & 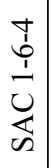 & 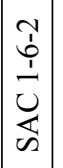 & 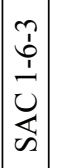 & 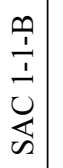 & 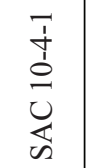 & \begin{tabular}{l}
+ \\
$\infty$ \\
$\infty$ \\
$\infty$ \\
$u$ \\
\multirow{4}{\infty}{}
\end{tabular} & 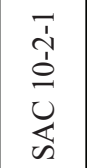 & $\begin{array}{l}\frac{m}{1} \\
\frac{1}{U} \\
\text { 崩 }\end{array}$ \\
\hline 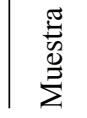 & $\vec{n}$ & No & $\begin{array}{l}m \\
n \\
n\end{array}$ & $\begin{array}{l}+ \\
\text { con }\end{array}$ & $\begin{array}{l}0 \\
\text { 年 }\end{array}$ & is & $\begin{array}{l}\infty \\
\infty \\
1 \\
1\end{array}$ & $\begin{array}{l}0 \\
\tilde{n} \\
-1\end{array}$ & $\left|\begin{array}{l}0 \\
0 \\
0 \\
-1\end{array}\right|$ & $\begin{array}{l}\exists \\
\tilde{n} \\
\underline{1}\end{array}$ & $\frac{1}{3}$ & $\frac{m}{3}$ & $\frac{\pi}{\sqrt{3}}$ & $\begin{array}{l}\text { N } \\
\text { s }\end{array}$ \\
\hline
\end{tabular}

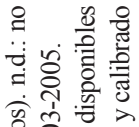

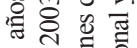

तิ $\frac{\pi}{\pi} \cdot \frac{0}{0} \cdot \frac{0}{0}$

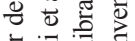

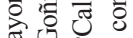

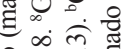

을 完宽总

यदं तं च.

के चे 0

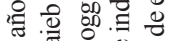

- 펼 过

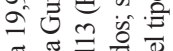

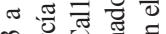

气

चั่

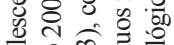

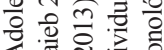

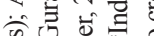

爱

ते

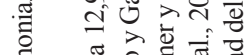

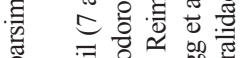

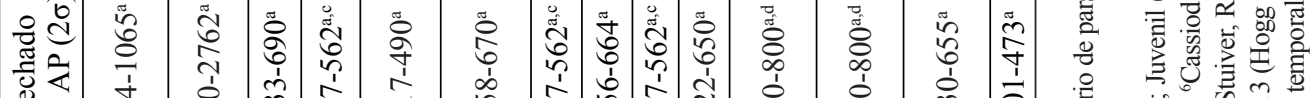

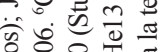

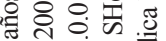

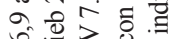

.융

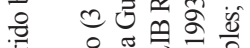

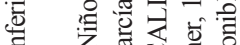

ज्ञ

iे

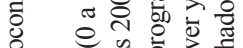

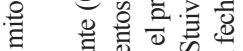

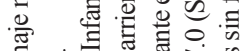

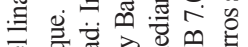

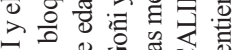

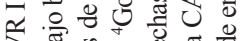

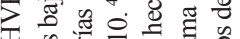

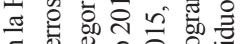
ปี

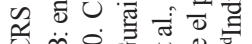
论

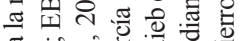

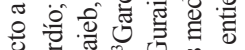
. ज्ञ

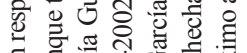

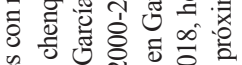
ษ

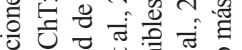
迎

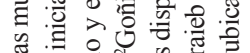

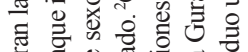

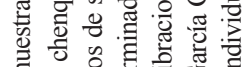

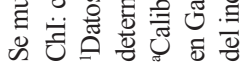




\begin{tabular}{|c|c|c|c|c|c|c|c|c|c|c|c|c|c|c|}
\hline 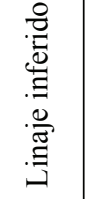 & 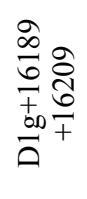 & 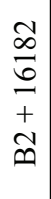 & $\stackrel{\vec{g}}{\dot{g}}$ & $\stackrel{\check{I}}{\dot{I}}$ & $\begin{array}{l}\dot{d} \\
\dot{g}\end{array}$ & $\stackrel{\vec{I}}{\vec{I}}$ & 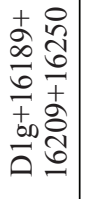 & $\dot{\check{g}}$ & $\stackrel{\vec{\Xi}}{\dot{I}}$ & $\stackrel{\check{g}}{\dot{I}}$ & 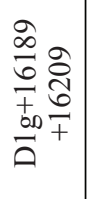 & $\stackrel{\overrightarrow{\dot{d}}}{\dot{\Xi}}$ & $\stackrel{\overrightarrow{\dot{j}}}{\dot{\mathrm{j}}}$ & $\stackrel{\vec{I}}{\dot{I}}$ \\
\hline 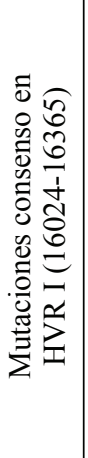 & 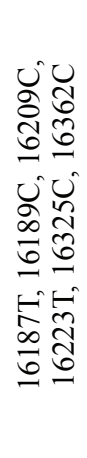 & 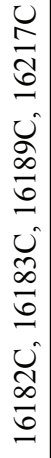 & 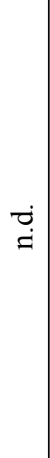 & $\stackrel{\ddot{I}}{\dot{I}}$ & $\begin{array}{l}\dot{I} \\
\dot{I}\end{array}$ & $\stackrel{\check{J}}{\dot{J}}$ & 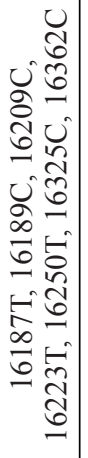 & $\stackrel{\vec{\jmath}}{\dot{g}}$ & $\stackrel{\vec{\Xi}}{\dot{I}}$ & تُ & 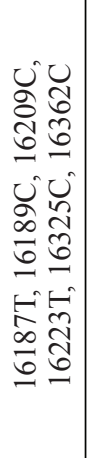 & $\stackrel{\overrightarrow{\dot{U}}}{\dot{\Xi}}$ & $\stackrel{\overrightarrow{\dot{j}}}{\dot{\mathrm{I}}}$ & $\stackrel{\check{I}}{\dot{I}}$ \\
\hline 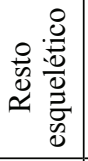 & $\begin{array}{l}\frac{\tilde{a}}{0} \\
\stackrel{\Xi}{0}\end{array}$ & 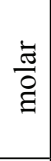 & 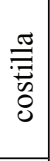 & 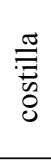 & 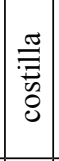 & 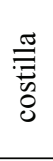 & $\begin{array}{l}\stackrel{ \pm}{0} \\
\stackrel{\Xi}{\Xi}\end{array}$ & $\begin{array}{l}\stackrel{0}{=} \\
\bar{ت} \\
0 \\
0 \\
0\end{array}$ & $\begin{array}{l}\frac{\bar{t}}{0} \\
\stackrel{\Xi}{a}\end{array}$ & 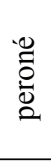 & $\begin{array}{l}\frac{\text { สี }}{0} \\
\text { ! }\end{array}$ & 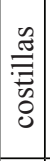 & 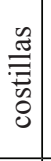 & 壹 \\
\hline
\end{tabular}

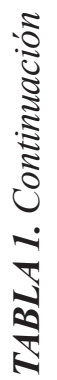

\begin{tabular}{|c|c|c|c|c|c|c|c|c|c|c|c|c|c|c|c|}
\hline 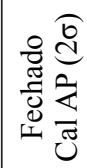 & 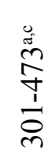 & 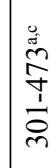 & $\begin{array}{l}0 \\
0 \\
0 \\
0 \\
0 \\
n\end{array}$ & 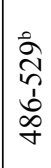 & 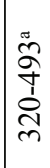 & 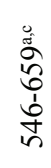 & 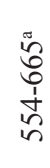 & 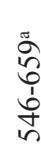 & 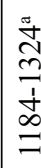 & ì & & & 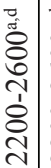 & & 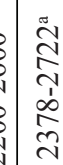 \\
\hline
\end{tabular}

\begin{tabular}{|c|c|c|c|c|c|c|c|c|c|c|c|c|c|c|}
\hline 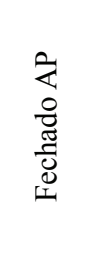 & 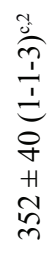 & 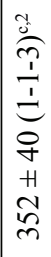 & 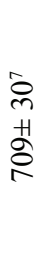 & 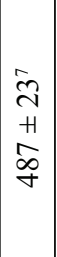 & 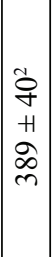 & 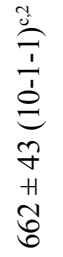 & $\begin{array}{l}\stackrel{+}{f} \\
+ \\
\tilde{\infty}\end{array}$ & 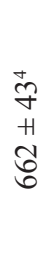 & \begin{tabular}{l} 
J \\
H \\
$\infty$ \\
$\infty$ \\
\multirow{+}{+}{}
\end{tabular} & 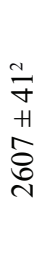 & $\begin{array}{l}\infty \\
\stackrel{\infty}{2} \\
H \\
\infty \\
\stackrel{N}{N}\end{array}$ & تே & $\stackrel{\check{I}}{\text { ¿ }}$ & 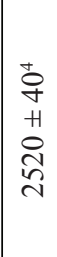 \\
\hline 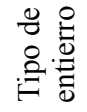 & E्ञ & $\vec{E}$ & లี & $\stackrel{E}{\Xi}$ & $\vec{t}$ & $\vec{E}$ & Eี & 㫐 & 를 & $\begin{array}{l}\frac{8}{0} \\
\frac{0}{Z}\end{array}$ & $\stackrel{\vec{U}}{\mathrm{U}}$ & $\mid$\begin{tabular}{l}
0 \\
$\frac{0}{0}$ \\
\hdashline \\
$z$
\end{tabular} & 劲 & $\begin{array}{l}\frac{9}{0} \\
: \frac{0}{7}\end{array}$ \\
\hline
\end{tabular}

\begin{tabular}{|c|c|c|c|c|c|c|c|c|c|c|c|c|c|c|}
\hline $\begin{array}{l}\overrightarrow{\tilde{T}} \\
\vec{I}\end{array}$ & 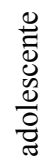 & $\begin{array}{l}\bar{\Xi} \\
\text { 泀 } \\
\end{array}$ & $\begin{array}{l}\stackrel{\mathscr{U}}{\tilde{I}} \\
\stackrel{\text { I }}{\Xi}\end{array}$ & 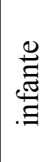 & 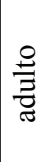 & !目 & $\begin{array}{l}\bar{\Xi} \\
\bar{\Xi}\end{array}$ & 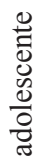 & $\frac{\stackrel{\rho}{\underline{Z}}}{\frac{7}{\tilde{d}}}$ & $\frac{\text { 올 }}{\text { ? }}$ & $\frac{\stackrel{\rho}{\Xi}}{\frac{7}{\sigma}}$ & $\frac{\text { 올 }}{\text { 홍 }}$ & $\frac{?}{\frac{\rho}{z}}$ & $\frac{?}{\frac{7}{7}}$ \\
\hline
\end{tabular}

\begin{tabular}{|c|c|c|c|c|c|c|c|c|c|c|c|c|c|c|}
\hline $\begin{array}{l}\overrightarrow{0} \\
\dot{x} \\
\tilde{u}\end{array}$ & 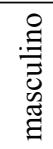 & 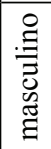 & $\underset{\dot{g}}{\dot{d}}$ & $\stackrel{\check{g}}{\dot{I}}$ & 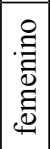 & 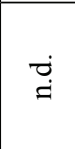 & 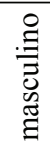 & 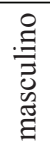 & 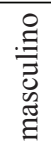 & $\stackrel{\dot{\Xi}}{\dot{\Xi}}$ & 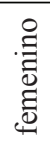 & 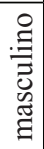 & 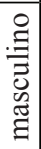 & \\
\hline 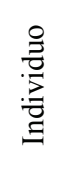 & $\begin{array}{l}\frac{T}{1} \\
\frac{1}{U} \\
\stackrel{4}{4}\end{array}$ & 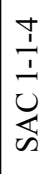 & \begin{tabular}{c}
$n$ \\
$\dot{1}$ \\
$\dot{1}$ \\
$\dot{U}$ \\
\multirow{4}{\sim}{} \\
$\omega$
\end{tabular} & 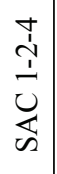 & 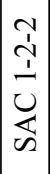 & 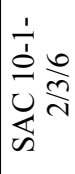 & 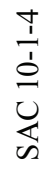 & $\begin{array}{l}\frac{1}{1} \\
0 \\
0 \\
\frac{1}{d}\end{array}$ & 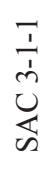 & 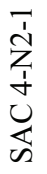 & $\begin{array}{l}\vec{I} \\
\dot{+} \\
\dot{U} \\
\stackrel{4}{\Delta}\end{array}$ & 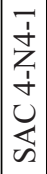 & 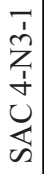 & 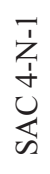 \\
\hline $\begin{array}{l}\underset{\mathbb{E}}{\tilde{E}} \\
\stackrel{\Xi}{\Xi}\end{array}$ & $\begin{array}{l}\bar{N} \\
\tilde{n}\end{array}$ & $\begin{array}{l}\tilde{3} \\
\text { ב } \\
-1 \\
-1\end{array}$ & $\begin{array}{l}\tilde{n} \\
\tilde{3} \\
-1\end{array}$ & $\begin{array}{l}\mathbb{J} \\
0 \\
0\end{array}$ & $\begin{array}{c}2 \\
1 \\
0 \\
-1 \\
-1\end{array}$ & $\begin{array}{l}\text { i } \\
\text { s } \\
\text { s }\end{array}$ & $\begin{array}{l}\hat{N} \\
\tilde{N}\end{array}$ & $\begin{array}{l}\stackrel{\infty}{N} \\
\text { యి }\end{array}$ & 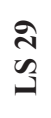 & ले & $\begin{array}{l}\bar{m} \\
\tilde{1}\end{array}$ & लె & 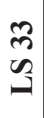 & ले \\
\hline
\end{tabular}

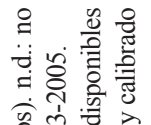

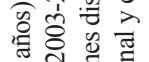

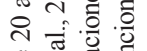

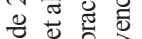

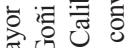

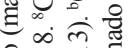

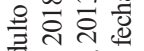

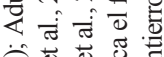

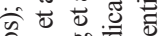

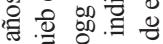

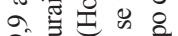

o 0 is

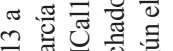

包芯焉

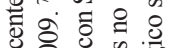

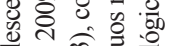

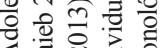

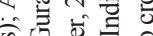

, 물

氙 $\cong$

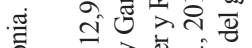

$\approx$ ว

ᄃ

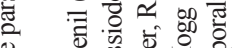

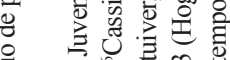

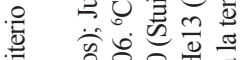

के क्ते

a. 0 i

.유

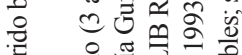

离结总灾氙

严

हैंड

¿ $\quad$ के

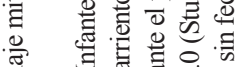

范品焉

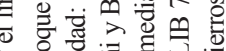

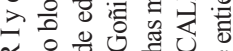

可

๘

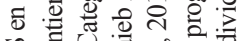

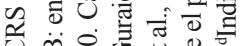

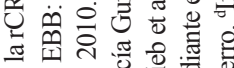

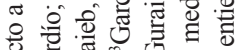

要

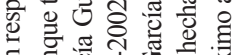

ठํ

论

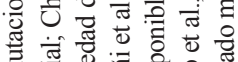

莽

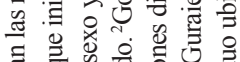

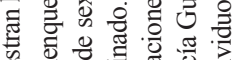

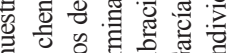

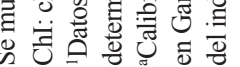


TABLA 2. Estadísticos de variabilidad genética obtenidos para las poblaciones antiguas analizadas

\begin{tabular}{ccccccc}
\hline Población & $\mathrm{n}$ & $\mathrm{h}$ & $\mathrm{Hd}$ & $\pi$ & $\theta_{\mathrm{s}}$ & $\mathrm{k}$ \\
\hline Norpatagonia & 15 & 9 & $0,924(0,044)$ & $0,01571(0,00123)$ & 0,018 & 5,371 \\
\hline Costa de Santa Cruz & 5 & 4 & $0,900(0,161)$ & $0,01754(0,00337)$ & 0,015 & 6,000 \\
\hline Lago Salitroso & 16 & 12 & $0,950(0,041)$ & $0,01693(0,00154)$ & 0,018 & 5,792 \\
\hline Kawéskar & 20 & 11 & $0,921(0,037)$ & $0,01484(0,00153)$ & 0,013 & 5,074 \\
\hline Yámana & 27 & 10 & $0,809(0,064)$ & $0,01000(0,00198)$ & 0,013 & 3,419 \\
\hline Total & 83 & 35 & $0,951(0,011)$ & $0,01668(0,00070)$ & 0,023 & 5,703 \\
\hline
\end{tabular}

n: tamaño muestral; h: número de haplotipos; Hd: diversidad haplotípica (desvio estandar); $\pi$ : diversidad nucleotídica (desvio estandar); $\theta \mathrm{s}$ : estimador de Watterson; k: número promedio de diferencias nucleotídicas.

TABLA 3. Resultado del AMOVA realizado con las poblaciones arqueológicas de la Patagonia

\begin{tabular}{ccccc}
\hline Fuente de variación & g.l. & Suma de cuadrados & Componentes de la varianza & Porcentaje de variación \\
\hline Entre poblaciones & 4 & 58,762 & 0,753 & $21,31^{*}$ \\
Dentro de poblaciones & 78 & 216,774 & 2,779 & 78,69 \\
\hline Total & 82 & 275,536 & 3,532 & 100 \\
\hline
\end{tabular}

g.1.: grados de libertad. ${ }^{*} \mathrm{p}<0,00001$.

raciones entre pares de grupos a través del cálculo de los $\mathrm{F}_{\mathrm{ST}}$ linealizados muestran que la población del Lago Salitroso se diferencia significativamente $(\mathrm{p}<0,05)$ de todas las poblaciones antiguas consideradas en el estudio, siendo mayores las diferencias con poblaciones insulares (Yámana y Kawéskar), y menores con las continentales (Fig. 2; Material suplementario, Tabla S3).

\section{Distribución de los haplotipos encontrados}

En líneas generales, en las redes de haplotipos construidas se destaca la presencia en la población del Lago Salitroso tanto de linajes centrales, muy frecuentes en poblaciones antiguas y actuales de la región, como de haplotipos derivados que en su mayoría fueron hallados únicamente en la cuenca. Cabe destacar que se está analizando sólo la HVR I, por lo que resulta probable que algunas de las muestras analizadas posean polimorfismos derivados por fuera de la región mitocondrial estudiada.
En el caso del haplogrupo C1 (Fig. 3) el haplotipo del individuo LS 6 no es compartido con otra población, si bien comparte una mutación en la posición 16266 con un individuo mapuche actual (de Saint Pierre et al., 2012a). Este último pertenece al subhaplogrupo C1b13, lo cual podría sugerir su presencia en el Lago Salitroso. Sin embargo, para poder concluir al respecto es necesario ampliar el rango de análisis a fin de incluir las posiciones 258 y 7091 , que son diagnósticas para este linaje (de Saint Pierre et al., 2012b). Por otro lado, llama la atención que en otro individuo del Lago Salitroso (LS 13) se halló un haplotipo descripto también para un individuo de Puerto San Julián, en la costa de Santa Cruz $(\mathrm{C} 1+16171$; Crespo et al., 2017b).

La red realizada con el linaje D1 (Fig. 4) presenta una topología multimodal, asociada a la alta frecuencia del linaje D1g (Bodner et al., 2012) en poblaciones patagónicas. En efecto, la mayoría de los individuos del Lago Salitroso posee dicho linaje, compartido con individuos 


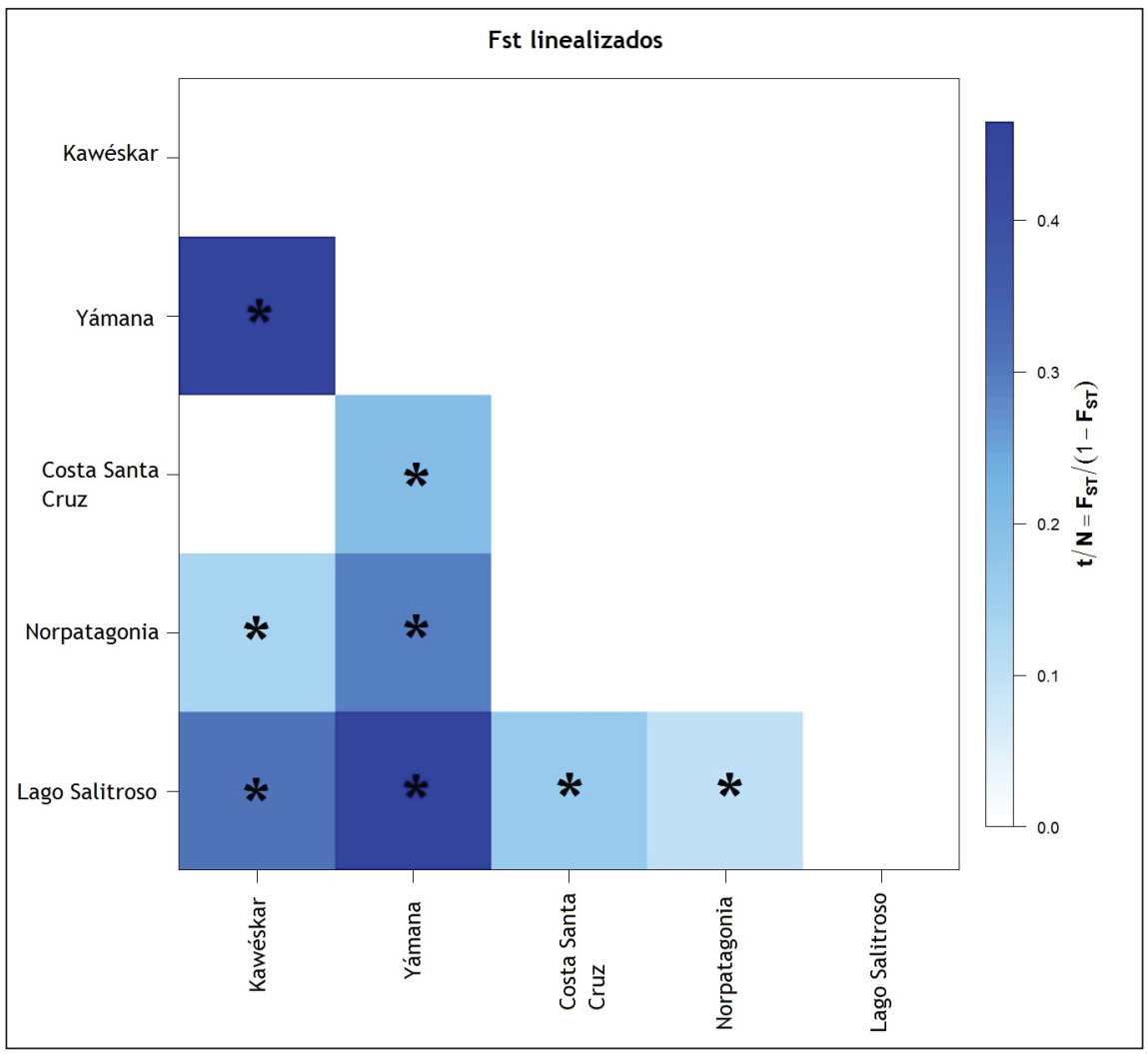

Fig. 2. Comparaciones de a pares $\left(\mathrm{F}_{\mathrm{ST}}\right)$ entre los grupos poblacionales prehispánicos estudiados, linealizadas por el método de Slatkin. ${ }^{*} \mathrm{p}<0,05$.

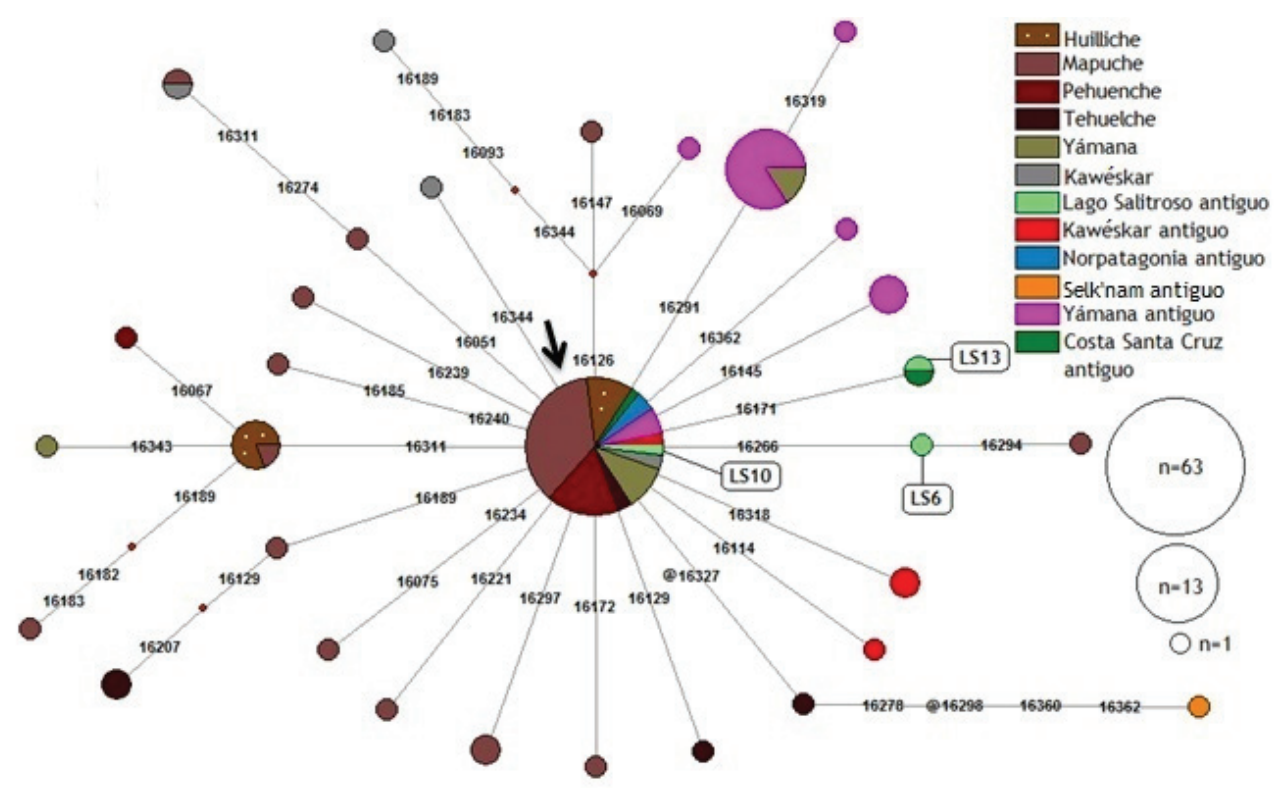

Fig. 3. Red de haplotipos del linaje C1 según la HVR I. @ indica sitios revertantes. La flecha indica el haplotipo $\mathrm{C} 1$ nodal, definido por mutaciones en las posiciones $16223,16298,16325$ y 16327 respecto a la rCRS. 


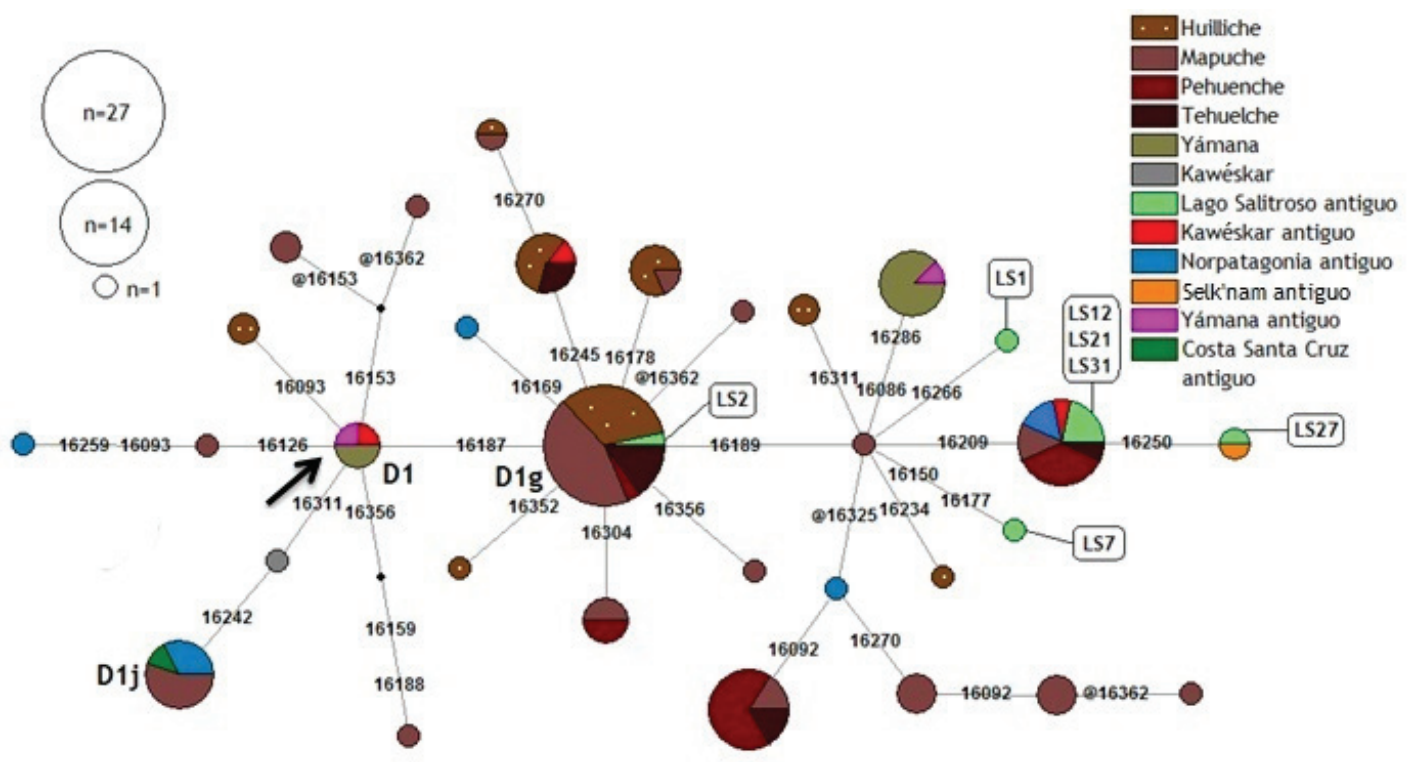

Fig. 4. Red de haplotipos del linaje D1 según la HVR I. @ indica sitios revertantes. La flecha indica el haplotipo D1 nodal, definido por mutaciones en las posiciones $16223,16325,16362$ respecto a la rCRS.

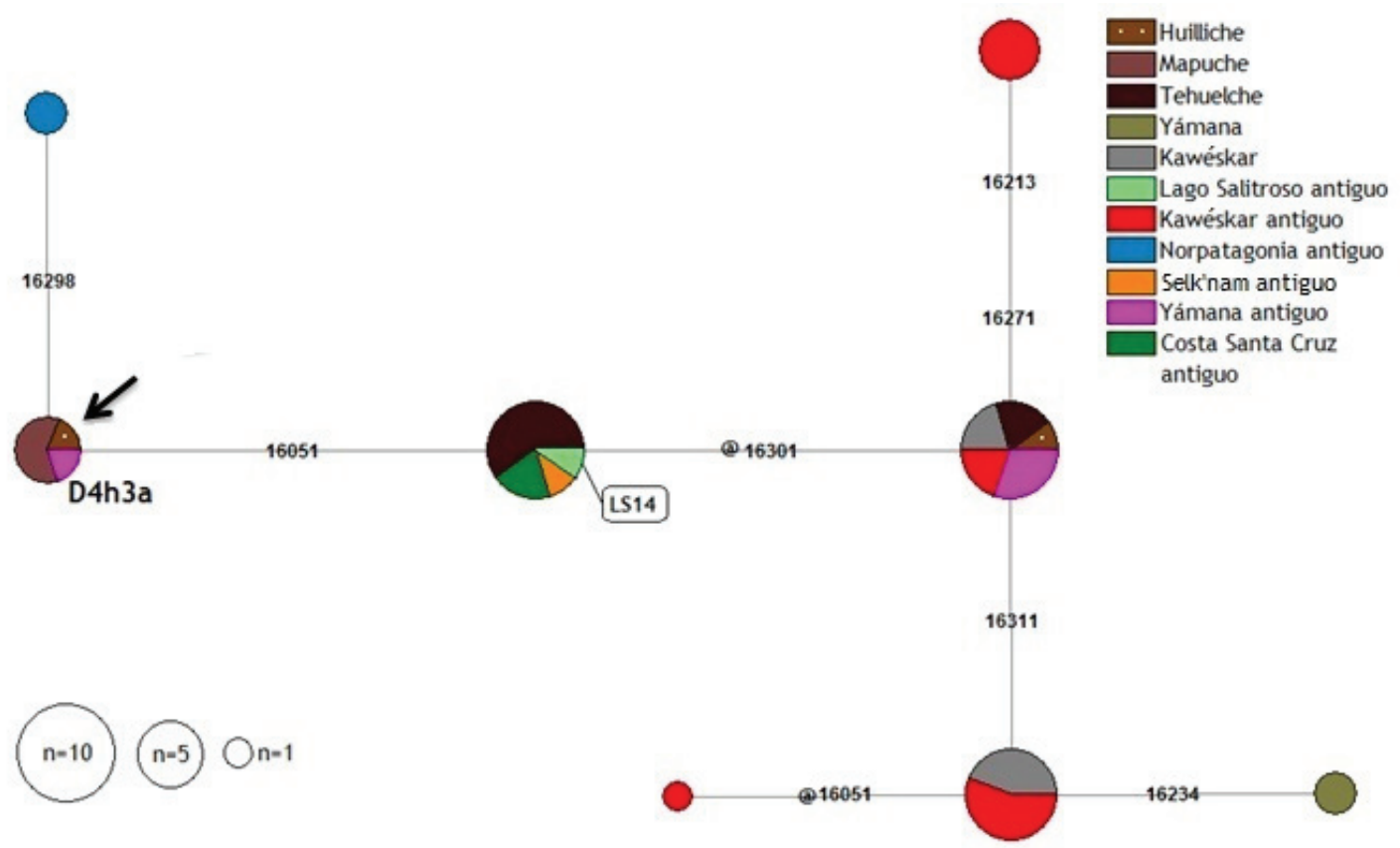

Fig. 5. Red de haplotipos del linaje D4h3a según la HVR I. @ indica sitios revertantes. La flecha indica el haplotipo D4h3a nodal, definido por mutaciones en las posiciones 16223, 16241, 16301, 16342 y 16362 respecto a la rCRS. 
de poblaciones actuales, así como la variante $\mathrm{D} 1 \mathrm{~g}+16189+16209$, presente en poblaciones tanto prehispánicas como actuales. El resto de los individuos de esta población presentó haplotipos con mutaciones adicionales no halladas en la base de datos, y únicamente LS 27 resultó tener la misma variante que un Selk'nam prehispánico (D1g+16189+16209+16250; Raghavan et al., 2015).

El linaje D4h3a (Fig. 5) fue hallado solo en un individuo de la población del Lago Salitroso, cuyo haplotipo es compartido con un individuo Selk'nam antiguo (D4h3a+16051; Raghavan et al., 2015), dos individuos de la costa de Santa Cruz antiguos (Crespo et al., 2017a; Motti et al., 2015), y Tehuelches actuales (de Saint Pierre et al., 2012a).

Finalmente, la red construida para los haplotipos B2 (Fig. 6) muestra que cuatro de los cinco individuos del lago con dicho linaje comparten el haplotipo central. Por otro lado, LS 11 (B2+16362) posee un haplotipo particular no compartido con individuos de ninguna otra población patagónica. Cabe destacar que en este caso, los linajes del Lago Salitroso pudieron ser comparados únicamente con poblaciones actuales, puesto que el haplogrupo B2 no se halló en ninguna de las poblaciones prehispánicas de Patagonia con información disponible en bibliografía.

\section{Pruebas de expansión poblacional}

No se hallaron evidencias de expansión poblacional en el Lago Salitroso puesto que tanto el valor del D $(-0,12803)$ como el de Fs $(0,40195)$ resultaron ser no significativos $(\mathrm{p}=0,57200$ y $\mathrm{p}=0,42700$ respectivamente).

\section{DISCUSIÓN}

\section{Variabilidad genética de la población humana del Lago Salitroso}

A nivel mitocondrial, la población prehispánica del Lago Salitroso presenta características particulares que la diferencian de otras poblaciones patagónicas. Por ejemplo, si bien la alta frecuencia del linaje D1g (43,7\%) resultaba esperable ya que es un linaje altamente representado en la Patagonia tanto al este como al oeste de la Cordillera de los Andes (de Saint Pierre et al., 2012a), la asignación de un total de cinco individuos $(31,3 \%)$ al haplogrupo B2 resulta altamente llamativa. Esto se debe a que los estudios realizados en poblaciones nativas actuales detectan este haplogrupo hasta Patagonia Septentrional (de Saint Pierre et al., 2012 a y b; Moraga et al., 2000). Sin embargo, este hallazgo se relaciona con los resultados obtenidos por Reyes et al. (2012) en la Patagonia

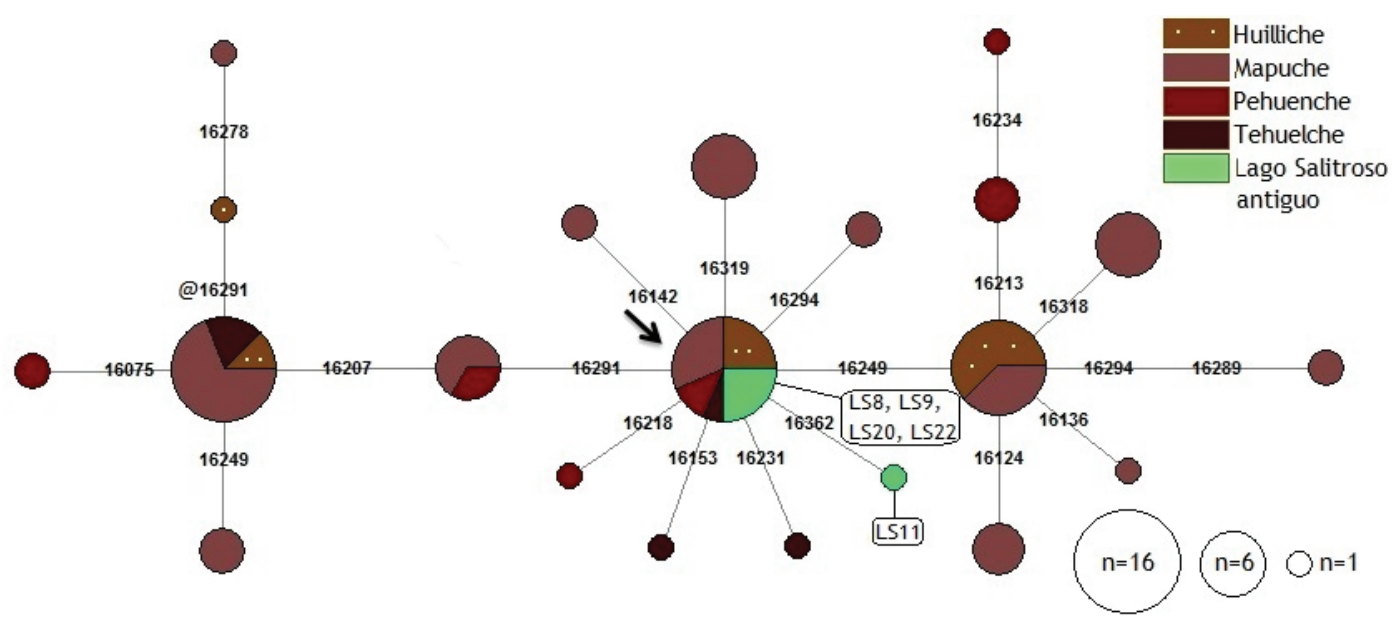

Fig. 6. Red de haplotipos del linaje B2 según la HVR I. No se tuvieron en cuenta las posiciones 16182 y 16183 para la confección de la red. La flecha indica el haplotipo B2 nodal, definido por mutaciones en las posiciones 16189 y 16217 respecto a la rCRS. 
chilena y Franco et al. (2017) en Santa Cruz, donde la alta representación del haplogrupo B2 sugiere que este linaje se encontraba presente en los primeros pobladores de la región, o bien su presencia en grupos más tardíos del sur (como en la población del Lago Salitroso) se debería a un poblamiento posterior desde Norpatagonia. Por lo tanto, su ausencia en la gran mayoría de las poblaciones prehispánicas y actuales de tan altas latitudes podría no ser causa de la pérdida del linaje por efecto de la deriva genética en el poblamiento inicial hacia el sur. En cambio, podría sugerirse un posible sesgo muestral en las poblaciones analizadas, tanto actuales como antiguas, o bien la pérdida más reciente del linaje por algún proceso microevolutivo posiblemente asociado a la conquista europea.

Considerando la disminución hacia el sur de la variabilidad genética mitocondrial planteada a escala continental, los resultados de este trabajo (Tabla 2) muestran que, para el contexto patagónico, la reducción más marcada se observa únicamente en poblaciones insulares pero no así en continentales como se pensaba (García-Bour et al., 2004; Moraga et al., 2000). De esta manera, los altos niveles de variabilidad observados en el Lago Salitroso podrían tomarse como evidencia de que las poblaciones del sur de la Patagonia continental poseían una mayor diversidad respecto a lo que se conocía hasta el momento, y que la deriva génica sí habría actuado de manera más acentuada sobre las poblaciones insulares debido a su aislamiento geográfico. Dado que la mayoría de los resultados disponibles de otras poblaciones antiguas de la región son de individuos aislados de diferentes períodos cronológicos, resulta necesario continuar los muestreos para contextualizar y ayudar a corroborar esta hipótesis.

\section{Distribución de linajes y diferenciación de la población del Lago Salitroso}

Según el modelo arqueológico de poblamiento planteado por Borrero (2001) y Goñi (2010), la Patagonia presenta un escenario geográfico en el cual las barreras biogeográficas y la baja demografía de las poblaciones cazadoras recolectoras habrían llevado a divergencias poblacionales. Acorde a esto, el análisis de subestructuración poblacional indica diferencias significativas entre las poblaciones antiguas analizadas (Tabla 3). El caso particular de la diferenciación de la población del Lago Salitroso con respecto al resto de los grupos prehispánicos patagónicos (Fig. 2) podría explicarse principalmente por la mencionada presencia del haplogrupo B2, ausente en el resto de las poblaciones prehispánicas incluidas en el análisis, así como por la presencia de haplotipos derivados no compartidos con otras poblaciones en el caso de los haplogrupos C1 (Fig. 3) y D1 (Fig. 4).

Sin embargo, existen linajes compartidos entre la población del Lago Salitroso y otras poblaciones antiguas. El hecho de que los individuos de los cuales provienen las muestras LS 13, LS 14 y LS 27 compartan su haplotipo con otros individuos prehispánicos de las poblaciones Selk'nam y de la costa de Santa Cruz permite plantear un posible vínculo entre las regiones, debido por ejemplo a un ancestro materno común o a un contacto poblacional (Borrero, Martin y Barberena, 2011; Goñi, 2013; Crespo, Lanata, Cardozo, Avena y Dejean, 2018).

Por último, uno de los individuos con haplogrupo B2 presenta polimorfismos no reportados hasta el momento en ninguna población actual de la Patagonia (Fig. 6), remarcando la singularidad y diversidad de la población, así como la importancia de ampliar los análisis de restos antiguos.

\section{¿Crecimiento poblacional de la población del Lago Salitroso?}

La sobrerrepresentación de subadultos en la colección osteológica de los chenques tardíos (800 a 350 años cal AP) del Lago Salitroso llevó a plantear un posible escenario de expansión o recuperación poblacional luego de la ACM (García Guraieb, 2010). Sin embargo, los análisis estadísticos realizados en el presente trabajo no muestran un correlato genético de ese escenario. Es posible que un crecimiento poblacional reciente no haya dejado huellas genéticas lo suficientemente fuertes como para ser detectadas con la metodología empleada. Por lo tanto, se plantea profundizar estos análisis a futuro incorporando más individuos, utilizando métodos con enfoques probabilísticos sobre distintas regiones del genoma mitocondrial puesto que pueden variar los resultados (Postillone y Perez, 
2017), y contrastando los resultados con otras poblaciones que posean evidencia de expansión.

\section{Escenarios demográficos posibles para la cuenca del Lago Salitroso}

La información recabada desde las distintas líneas de evidencia sugiere diversos escenarios posibles para la conformación de la población del Lago Salitroso, hace aproximadamente 2600 años cal AP. Por ejemplo, puede plantearse un origen múltiple a partir de diversos grupos locales de cazadores recolectores con ciertos niveles de flujo génico previo entre ellos, y altos niveles de variabilidad respecto a lo esperado para la región. Por otro lado, pudo haberse dado una relocalización de una única población asentada previamente en otra región patagónica, con cierto grado de diferenciación genética del resto de las poblaciones y altos niveles de variabilidad. A este respecto, la actual provincia de Santa Cruz posee registro de ocupaciones estables desde momentos tempranos del poblamiento (Perez et al., 2016) y evidencia isotópica que avala la existencia de nodos poblacionales hacia el interior de la estepa (Gordón, Tessone, Beguelin, Arrigoni y Guichón, 2015; Tessone, 2010).

Sin embargo, la mayor parte de la información genética disponible de la población de la cuenca del Lago Salitroso y analizada en este trabajo corresponde temporalmente al final de la ACM y años posteriores (Tabla 1). Por ende, cabe la posibilidad de que la alta variabilidad observada no sea una característica de la población inicial del lago, sino debido a una alta afluencia de migrantes atraídos posteriormente a la cuenca como consecuencia de las sequías extremas ocurridas durante la ACM. Este proceso podría ser evaluado mediante el análisis de la diversidad genética del lago en tiempos tempranos y su comparación con la de tiempos tardíos.

\section{CONCLUSIONES}

La alta concentración de entierros humanos en el Lago Salitroso durante el Holoceno tardío permitió disponer de una muestra de gran tamaño y estimar la variabilidad genética a escala poblacional. Los niveles encontrados son altos respecto a los esperados según el patrón de re- ducción hacia el sur propuesto en trabajos previos. Por lo tanto, no es posible concluir acerca de una disminución de la variabilidad hacia el sur de la Patagonia en su conjunto, sino únicamente para el caso de poblaciones insulares.

Por otro lado, las diferencias a nivel genético encontradas entre las poblaciones antiguas analizadas (Tabla 3) son consistentes con el modelo arqueológico de poblamiento planteado por Borrero (2001) y Goñi (2010). Particularmente, la diferenciación genética de la población del lago respecto del resto de las poblaciones analizadas podría deberse tanto a la alta variabilidad como a la presencia en alta frecuencia del haplogrupo B2, escasamente reportado hasta el momento en grupos cazadores recolectores prehispánicos de la región. En este sentido, su descubrimiento en tal frecuencia en una población antigua austral tiene fuertes implicancias en cuanto a los modelos de poblamiento y continuidad de los linajes maternos hasta la actualidad en la Patagonia.

Si bien los últimos análisis bioarqueológicos sugieren un crecimiento poblacional durante los últimos 500 años de ocupación de la cuenca, no se encontraron evidencias genéticas de dicho proceso. Esto indica que es posible que otros procesos demográficos expliquen las características genéticas de la población del Lago Salitroso.

Es necesario tener en cuenta que sólo se analizó el linaje materno de los individuos. Es posible que el estudio de linajes paternos y marcadores biparentales indiquen patrones diferentes, dando cuenta de otros procesos y patrones demográficos, tales como la matri o patrilocalidad de las poblaciones.

\section{Nota}

${ }^{1}$ Sedentarización relativa de grupos locales en loci puntuales, provocando un aumento local de la población (Goñi et al., 2000-2002).

\section{AGRADECIMIENTOS}

Agradecemos al CEBBAD (Universidad Maimónides) y a la Sección de Antropología Biológica de la FFyL (UBA). También agradecemos a la Fundación Científica Felipe Fiorellino, a la Fundación de Historia Natural Félix Azara, CONICET, INAPL, UBACyT y a 
la ANPCyT por el apoyo financiero brindado. Por último, a la editora y a los dos revisores anónimos por las sugerencias que ayudaron a mejorar este artículo.

\section{LITERATURA CITADA}

Achilli, A., Perego, U. A., Lancioni, H., Olivieri, A., Gandini, F., Kashani, B. H...... Torroni, A. (2013). Reconciling migration models to the Americas with the variation of North American native mitogenomes. Proceedings of the National Academy of Sciences, 110(35), 14308-14313. doi:10.1073/pnas.1306290110

Andrews, R. M., Kubacka, I., Chinnery, P. F., Lightowlers, R. N. y Turnbull, D. M. (1999). Reanalysis and revision of the Cambridge reference sequence for human mitochondrial DNA. Nature Genetics, 23, 147. doi: $10.1038 / 13779$

Arencibia, V. (2018). Análisis genético poblacional aplicado al estudio de grupos cazadores recolectores prehispánicos del Lago Salitroso (Santa Cruz, Argentina) (Tesis de Licenciatura en Cs. Biológicas). Facultad de Ciencias Exactas y Naturales, Universidad de Buenos Aires.

Ariztegui, D., Gilli, A., Anselmetti, F., Goñi, R., Belardi, J. y Espinosa, E. (2010). Lake level changes in Central Patagonia (Argentina): Crossing environmental thresholds for Late Glacial and Holocene human occupation. Journal of Quaternary Science, 25(7), 1092-1099. doi:doi. org/10.1002/jqs.1352

Bandelt, H. J., Forster, P. y Röhl, A. (1999). Median-joining networks for inferring intraspecific phylogenies. Molecular Biology and Evolution, 16(1), 37-48. doi:10.1093/ oxfordjournals.molbev.a026036

Beguelin, M. (2009). Variación geográfica en la morfología del esqueleto postcraneal de las poblaciones humanas de Pampa y Patagonia durante el Holoceno Tardio: Una aproximación morfométrica (Tesis Doctoral). Facultad de Ciencias Naturales y Museo, Universidad Nacional de La Plata, La Plata.

Bernal, V. (2008). Procesos de diferenciación biológica entre poblaciones humanas del Holoceno Tardio de Patagonia. Una aproximación desde la variación morfométrica dental (Tesis Doctoral). Facultad de Ciencias Naturales y Museo, Universidad Nacional de La Plata, La Plata.

Bodner, M., Perego, U. A., Huber, G., Fendt, L., Röck, A. W., Zimmermann, B. ....... Parson, W. (2012). Rapid coastal spread of first Americans: novel insights from South America's Southern cone mitochondrial genomes. Genome Research, 22(5), 811-820. doi:10.1101/ gr.131722.111

Borrero, L. A. (2001). El poblamiento de la Patagonia. Toldos, milodones y volcanes. Buenos Aires, Argentina: Emecé editores.

Borrero, L. A., Martin, F., y Barberena, R. (2011). Visits, "Fuegians," and information networks. En: R. Whallon, W. A. Lovis y R. K. Hitchcock (Eds.), Information and its role in hunter-gatherer bands (pp. 249-265). California, USA: Leyba Associates.

Carnese, F. R., Mendisco, F., Keyser, C., Dejean, C. B., Dugoujon, J. M., Bravi, C. M., Ludes, B. y Crubezy, E. (2010). Paleogenetical study of pre-Columbian samples from Pampa Grande (Salta, Argentina). American Journal of Physical Anthropology, 141, 452-462. doi:10.1002/ajpa.21165
Cassiodoro, G. (2011). Movilidad y uso del espacio de cazadores-recolectores del Holoceno tardío: estudio de la variabilidad del registro tecnológico en distintos ambientes del noroeste de la provincia de Santa Cruz. BAR, Archaeopress, Oxford.

Cassiodoro, G., Aragone A. y Re, A. (2004). Más allá de los chenques...Registro arqueológico de sitios a cielo abierto en la cuenca de los lagos Salitroso y PosadasPueyrredón. En: M. T. Civalero, P. Fernández y G. A. Guraieb (Eds.), Contra Viento y Marea. Arqueología de la Patagonia (pp. 325-338). INAPL-SAA, Buenos Aires, Argentina.

Cassiodoro, G., y García Guraieb, S. (2009). Análisis del registro tecnológico y osteológico de los entierros humanos del Holoceno tardío del lago Salitroso (Santa Cruz): un aporte al estudio del comportamiento mortuorio de cazadores-recolectores. Arqueología de la Patagonia, 2, 613-628.

Crespo, C. M., Dubois, C. F., Russo, M. G., Lanata, J. L. y Dejean, C. B. (2017a). First analysis of ancient mtDNA genetic diversity in Northern coast of Argentinean Patagonia. Journal of Archaeological Science: Reports, 12, 91-98. doi:10.1016/j.jasrep.2017.01.011

Crespo, C. M., Russo, M. G., Hajduk, A., Lanata, J. L. y Dejean, C. B. (2017b). Variabilidad mitocondrial en muestras precolombinas de la Patagonia Argentina. Hacia una visión de su poblamiento desde el ADN antiguo. Revista Argentina de Antropología Biológica, 19 (1), 7-27. doi:10.17139/raab.2017.0019.01.07

Crespo, C. M., Lanata, J. L., Cardozo, D. G., Avena, S. A. y Dejean, C. B (2018). Ancient maternal lineages in hunter-gatherers groups of Patagonian Argentina. Settlement, population continuity and divergence. $J o$ urnal of Archaeological Science: Reports, 18, 689-695. doi:10.1016/j.jasrep.2017.11.003

de la Fuente, C., Galimany, J., Kemp, B., Judd, K., Reyes, O. y Moraga, M. (2015). Ancient marine hunter-gatherers from Patagonia and Tierra del Fuego: diversity and differentiation using uniparentally inherited genetic markers. American Journal of Physical Anthropology, 158, 719-729. doi:10.1002/ajpa.22815

De Nigris, M., Figuerero Torres, M. J., Guráieb A. G. y Mengoni Goñalons, G. L. (2004). Nuevos fechados radiocarbónicos de la localidad Cerro de los Indios I (Santa Cruz) y su proyección areal. En: M.T. Civalero, P. Fernández y G.A. Guraieb (Eds.), Contra Viento y $\mathrm{Ma}$ rea. Arqueología de la Patagonia (pp. 537-544). INAPLSAA, Buenos Aires, Argentina.

de Saint Pierre, M., Bravi, C., Motti, J., Fuku, N., Tanaka, M., Llop, E., Bonatto, S. L. y Moraga, M. (2012a). An alternative model for the early peopling of Southern South America revealed by analyses of three mitochondrial DNA haplogroups. Plos One, 7 (9):e43486. doi:10.1371/journal. pone.0043486

de Saint Pierre, M., Gandini, F., Perego, U., Bodner, M., Gómez-Carballa, A., Corach, D., ....... y Olivieri, A. (2012b). Arrival of Paleo-Indians to the Southern Cone of South America: New Clues from Mitogenomes. Plos One, 7(12):e51311. doi:10.1371/ journal.pone.0051311

Dejean, C. B., Crespo, C. M., Carnese, F. R. y Lanata, J. L. (2014). Ancient DNA research, scope and limitations. First genetic analysis in museum samples from San Julian, Santa Cruz, Argentina. En: D. Kligmann, M. Morales (Eds.). Physical, chemical and biological markers in Argentine archaeology: theory, methods and applications (pp. 53-62). Archaeopress, Oxford: British Archaeological Reports.

Excoffier, L. y Lischer, H. E. L. (2010). Arlequin suite ver 
3.5: A new series of programs to perform population genetics analyses under Linux and Windows. Molecular Ecology Resources, 10, 564-567. doi:10.1111/j.17550998.2010.02847.x

Franco, N. V., Galimany, J., Moraga, M. y Borrero, L. A. (2017). La integración de información cultural y genética en el sur de la cuenca superior del rio Santa Cruz: primeros resultados. X Jornadas de Arqueología de la Patagonia: Libro de resúmenes (p.15) / Julieta Gómez Otero ... [et al.]; J. Gómez Otero (Comp.). Puerto Madryn: Instituto de Diversidad y Evolución Austral, 2017.

Fu, Y. X. (1997). Statistical tests of neutrality of mutations against population growth, hitchhiking and background selection. Genetics, 147, 915-925.

García Guraieb, S. (2006). Salud y enfermedad en cazadores recolectores del Holoceno tardío en la cuenca del lago Salitroso (Santa Cruz). Intersecciones en Antropología, 7, 37-48

García Guraieb, S. (2010). Bioarqueología de cazadoresrecolectores del Holoceno tardio de la cuenca del lago Salitroso (Santa Cruz): aspectos paleopatológicos y paleodemográficos (Tesis Doctoral). Facultad de Filosofía y Letras, Universidad de Buenos Aires, Buenos Aires.

García Guraieb, S., Goñi, R. y Tessone, A. (2015). Paleodemography of Late Holocene hunter-gatherers from Patagonia (Santa Cruz, Argentina): an approach using multiple archaeological and bioarchaeological indicators. Quaternary International, 356, 147-158. doi:10.1016/j.quaint.2014.09.054

García Guraieb, S., Goñi, R. y Guichón Fernández, R. (2018). Aporte a la cronología de chenques tardíos del lago Salitroso (Santa Cruz, Argentina). Arqueología, 24(2), 271-280.

García-Bour, J., Pérez-Pérez, A., Álvarez, S., Fernández, E., López-Parra, A. M., Arroyo-Pardo, E. y Turbón, D. (2004). Early population differentiation in extinct aborigines from Tierra del Fuego-Patagonia: ancient mtDNA sequences and Y-chromosome STR characterization. American Journal of Physical Anthropology, 123, 361370. doi:10.1002/ajpa.10337

Goñi, R. (2000-2002). Fechados radiocarbónicos y registro arqueológico en la cuenca de los lagos Salitroso/Posadas (Santa Cruz). Cuadernos del Instituto Nacional de Antropología y Pensamiento Latinoamericano, 19 , 666-669.

Goñi, R. (2010). Cambio climático y poblamiento humano durante el Holoceno tardio en Patagonia Meridional. Una perspectiva arqueológica (Tesis Doctoral). Facultad de Filosofía y Letras, Universidad de Buenos Aires, Buenos Aires.

Goñi, R. (2013). Reacomodamientos poblacionales de momentos históricos en el noroeste de Santa Cruz. Proyecciones Arqueológicas. En: A. F. Zangrando, R. Barberena, A. Gil, G. Neme, M. Giardina, L. Luna, C. Otaola, S. Paulides, L. Salgán y A. Tivoli (Ed.), Tendencias teórico-metodológicas y casos de estudio en la Arqueología de Patagonia (pp. 389-396). Museo de Historia Natural de San Rafael, San Rafael, Argentina.

Goñi, R., Barrientos, G. y Cassiodoro, G. (2000-2002). Las condiciones previas a la extinción de las poblaciones humanas del sur de Patagonia: una discusión a partir del análisis de la estructura del registro arqueológico de la cuenca del Lago Salitroso. Cuadernos del Instituto Nacional de Antropología y Pensamiento Latinoamericano 19, 249-266.

Goñi, R., Bosio, L. A. y García Guraieb, S. (2003-2005). Un caso de enfermedad infecciosa en cazadores prehispánicos de Patagonia. Cuadernos del Instituto Nacional de Antropología y Pensamiento Latinoamericano 20, 399-404.

Goñi, R. y Barrientos, G. (2004). Poblamiento tardío y movilidad en la cuenca del lago Salitroso. En: M. T. Civalero, P. Fernández, G. A. Guraieb (Eds.), Contra viento y marea. Arqueología de Patagonia (pp. 313324). INAPL-SAA, Buenos Aires, Argentina.

Gordón, F., Tessone, A., Beguelin, M., Arrigoni, G. y Guichón, R. (2015). Paleodietas humanas en la costa patagónica durante el Holoceno Tardío. Nuevos datos de isótopos estables y fechados radiocarbónicos para la costa Centro-Sur. Intersecciones en Antropología, 16, 327-338.

Hogg, A. G., Hua, Q., Blackwell, P. G., Niu, M., Buck, C. E., Guilderson, T. P..... Zimmerman, S. R. H. (2013). SHCal13 Southern Hemisphere calibration, 0-50,000 years cal BP. Radiocarbon, 55 (4), 1889-1903.

Horta, L. y Aschero C. A. (2010). Evidencias de un paleolago Pleistoceno tardío-Holoceno temprano en el área del lago Pueyrredón, noroeste de la provincia de Santa Cruz. En: R. Bárcena y H. Chiavazza (Eds.), Arqueología Argentina en el Bicentenario de la Revolución de Mayo, XVII Congreso Nacional de Arqueología Argentina (pp. 1929-1934). Mendoza, Argentina: UNCuyoCONICET.

Kemp, B. M. y Smith, D. G. (2010). Ancient DNA Methodology: Thoughts from Brian M. Kemp and David Glenn Smith on "Mitochondrial DNA of protohistoric remains of an Arikara population from South Dakota". Human Biology, 82(2), 227-238. doi:10.3378/027.082.0207

Kuch, M., Grocke, D., Knyf, M., Gilbert, M., Younghusband, B., Young, T., Marshall, I., Willerslev, E., Stoneking, M. y Poinar, H. (2007). A preliminary analysis of the DNA and diet of the extinct beothuk: a systematic approach to ancient human DNA. American Journal of Physical Anthropology, 132, 594-604. doi:10.1002/ajpa.20536

Lalueza, C., Pérez-Pérez, A., Prats, E., Cornudella, L. y Turbón, D. (1997). Lack of founding amerindian mitochondrial DNA lineages in extinct aborigines from Tierra del Fuego-Patagonia. Human Molecular Genetics, 6(1), 41-46. doi:10.1093/hmg/6.1.41

Librado, P. y Rozas, J. (2009). DnaSP v5: a software for comprehensive analysis of DNA polymorphism data. Bioinformatics, 25 (11), 1451-1452. doi:10.1093/bioinformatics/btp 187

Moraga, M., Rocco, P., Miquel, J. F., Nervi, F., Llop, E., Chakraborty, R., Rothhammer, F. y Carvallo, P. (2000). Mitochondrial DNA polymorphisms in chilean aboriginal populations: implications for the peopling of the southern cone of the continent. American Journal of Physical Anthropology, 113, 19-29.

Moraga, M., de Saint Pierre, M., Torres, F. y Ríos, J. (2010). Vínculos de parentesco por vía materna entre los últimos descendientes de la etnia Kawéskar y algunos entierros en los canales patagónicos: evidencia desde el estudio de linajes mitocondriales. Magallania, 38(2), 103-114. doi: 10.4067/S071822442010000200006

Motti, J., Hagelberg, E., Lindo, J., Malhi, R., Bravi, C. y Guichón, R. (2015). Primer genoma mitocondrial en restos humanos de la costa de Santa Cruz, Argentina. Magallania, 43(2), 119-131. doi:10.4067/S071822442015000200006

Perez, I., Beguelin, M. y Del Papa, M. (2004). Evaluación de relaciones biológicas regionales y extraregionales de muestras del NO de Santa Cruz. En: M. T. Civalero, P. Fernández y A.G. Guraieb (Eds.), Contra Viento y Ma- 
rea. Arqueología de la Patagonia (pp.347-360). Buenos Aires, Argentina: INAPL-SAA.

Perez, S., Postillone, B., Rindel, D., Gobbo, D., González, P. y Bernal, V. (2016). Peopling time, spatial occupation and demography of late Pleistocene-Holocene human population from Patagonia. Quaternary International, 425, 214-223. doi:10.1016/j.quaint.2016.05.004

Postillone, M. B y Perez, S. I. (2017). Mitochondrial-DNA phylogenetic information and the reconstruction of human population history: the South American Case. Human Biology, 89(3), 229-250. doi:10.13110/humanbiology.89.3.05

Raghavan, M., Steinrücken, M., Harris, K., Schiffels, S., Rasmussen, S., DeGiorgio, M...... Willerslev, E. (2015). Genomic evidence for the Pleistocene and recent population history of Native Americans. Sciencexpress. doi:10.1126/science.aab3884

Reyes, O., Méndez Melgar, C., Mena, F. y Moraga, M. (2012). The bioanthropological evidence of a ca. 10,000 CALYBP ten-individual group in central Patagonia. En: L. Miotti, M. Salemme, N. Flegenheimer, T. Goebel (Eds.). Southbound: late Pleistocene peopling of Latin America (pp. 167-171). Center for the Study of the First Americans, Department of Anthropology, Texas, USA: Texas A \& M University.

Russo, M., Gheggi, M., Avena, S., Dejean, C. y Cremonte, M. (2017). Linajes mitocondriales en muestras de esquina de Huajra (Jujuy, Argentina). Aportes al estudio de la ocupación incaica en la región y la procedencia de sus habitantes. Revista Argentina de Antropología Biológica, 19(1). doi:10.17139/ raab.2017.0019.01.04

Slatkin, M. (1995). A measure of population subdivision based on microsatellite allele frequencies. Genetics, 139(1), 457-462.

Soares, P., Ermini, L., Thomson, N., Mormina, M., Rito, T., Röhl, A., Salas, A., Oppenheimer, S., Macaulay, V. y Richards, M. (2009). Correcting for purifying selection: an improved human mitochondrial molecular clock. American Journal of Human Genetics, 84(6), 740-759. doi:10.1016/j.ajhg.2009.05.001

Stine, S. (1994). Extreme and persistent drought in California and Patagonia during medieval time. Nature, 369 , 546-549.
Stine, S. y Stine, M. (1990). A record from Lake Cardiel of climate change in Southern America. Nature, 345, 705-708.

Stuiver, M. y Reimer, P. J. (1993). Extended 14C database and revised CALIB radiocarbon calibration program. Radiocarbon, 35, 215-230.

Stuiver, M., Reimer, P. J. y Reimer, R. (2013). CALIB 7.0.0. www. Program and Documentation. http://calib.qub. ac.uk/calib/

Tajima, F. (1989). The effect of change in population size on DNA polymorphism. Genetics, 123, 597-601.

Tamm, E., Kivisild, T., Reidla, M., Metspalu, M., Smith, D.G., Mulligan, C. J..... Malhi, R. S. (2007). Beringian standstill and spread of native American founders. Plos One, 2(9), e829. doi:10.1371/journal. pone. 0000829 .

Tamura, K. y Nei, M. (1993). Estimation of the number of nucleotide substitutions in the control region of mitochondrial DNA in humans and chimpanzees. Molecular Biology and Evolution, 10, 512-526.

Tamura, K., Stecher, G., Peterson, D., Filipski, A. y Kumar, S. (2013). MEGA6: Molecular Evolutionary Genetics Analysis version 6.0. Molecular Biology and Evolution, 30, 2725-2729. doi:10.1093/molbev/mst197

Tessone, A. (2010). Arqueología y Ecología Isotópica. Estudio de isótopos estables de restos humanos del Holoceno tardio en Patagonia meridional (Tesis Doctoral). Facultad de Filosofía y Letras, Universidad de Buenos Aires, Buenos Aires.

Tessone, A., Zangrando, F., Barrientos, G., Goñi, R., Panarello, H. y Cagnoni, M. (2009). Stable isotopes studies in the Salitroso Lake Basin (Southern Patagonia, Argentina): assessing diet on of Late Holocene hunter gatherers. International Journal of Osteoarchaeology, 19, 297-308. doi:10.1002/oa.1039

van Oven, M. y Kayser M. (2009). Updated comprehensive phylogenetic tree of global human mitochondrial DNA variation. Human Mutation, 30(2), E386-E394.

Weissensteiner, H., Pacher, D., Kloss-Brandstätter, A., Forer, L., Specht, G., Bandelt, H. J., Kronenberg, F., Salas, A. y Schönherr, S. (2016). HaploGrep 2: mitochondrial haplogroup classification in the era of high-throughput sequencing. Nucleic Acids Research, 44(W1), W58-W63. doi:10.1093/nar/gkw233 